\title{
Frontally mediated inhibitory processing and white matter microstructure: age and alcoholism effects
}

\author{
Ian M. Colrain • Edith V. Sullivan • Judith M. Ford • \\ Daniel H. Mathalon • Selwyn-Lloyd McPherson • \\ Brian J. Roach • Kate E. Crowley • Adolf Pfefferbaum
}

Received: 1 March 2010 /Accepted: 8 May 2010/Published online: 16 December 2010

(C) The Author(s) 2010. This article is published with open access at Springerlink.com

\begin{abstract}
Rationale The NOGO P3 event-related potential is a sensitive marker of alcoholism, relates to EEG oscillation in the $\delta$ and $\theta$ frequency ranges, and reflects activation of an inhibitory processing network. Degradation of white matter tracts related to age or alcoholism should negatively affect the oscillatory activity within the network.

Objective This study aims to evaluate the effect of alcoholism and age on $\delta$ and $\theta$ oscillations and the relationship between these oscillations and measures of white matter microstructural integrity.

Methods Data from ten long-term alcoholics to 25 nonalcoholic controls were used to derive P3 from $\mathrm{Fz}, \mathrm{Cz}$, and Pz using a visual GO/NOGO protocol. Total power and across trial phase synchrony measures were calculated for $\delta$ and $\theta$ frequencies. DTI, 1.5 T, data formed the basis of quantitative fiber tracking in the left and right cingulate bundles and the genu and splenium of the corpus callosum. Fractional anisotropy and diffusivity ( $\lambda \mathrm{L}$ and $\lambda \mathrm{T}$ ) measures were calculated from each tract.
\end{abstract}

I. M. Colrain $(\bowtie) \cdot$ K. E. Crowley $\cdot$ A. Pfefferbaum

SRI International,

333 Ravenswood Ave,

Menlo Park, CA 94025, USA

e-mail: ian.colrain@sri.com

E. V. Sullivan • A. Pfefferbaum

Stanford University School of Medicine,

Stanford, CA 94305, USA

J. M. Ford • D. H. Mathalon · S.-L. McPherson • B. J. Roach

University of California San Francisco,

San Francisco, CA 94121, USA
Results NOGO $\mathrm{P} 3$ amplitude and $\delta$ power at $\mathrm{Cz}$ were smaller in alcoholics than controls. Lower $\delta$ total power was related to higher $\lambda \mathrm{T}$ in the left and right cingulate bundles. GO P3 amplitude was lower and GO P3 latency was longer with advancing age, but none of the timefrequency analysis measures displayed significant age or diagnosis effects.

Conclusions The relation of $\delta$ total power at $\mathrm{CZ}$ with $\lambda \mathrm{T}$ in the cingulate bundles provides correlational evidence for a functional role of fronto-parietal white matter tracts in inhibitory processing.

Keywords Alcoholism · Age · P3 · DTI · MRI · Inhibition · Electrophysiology

Alcoholism is a disease characterized by impaired inhibitory control (Kamarajan et al. 2005a) often manifested as heightened impulsivity (Fox et al. 2008; Li et al. 2009) as is also seen in other forms of drug addiction (de Wit 2009). Inhibitory control is a key component of the executive functions mediated by the prefrontal cortex and modulated by a network of other regions including the anterior cingulate, motor, supplementary motor, and parietal cortices (Crews and Boettiger 2009; Oscar-Berman and Marinkovic 2007). The generation of a $P 3$ event-related potential (ERP) component in the context of a NOGO response inhibition task (Cohen et al. 1997b; Pfefferbaum et al. 1985) also involves activation of a network of brain regions associated with inhibitory behavior. While most of these investigations have implicated prefrontal or frontal regions (Barkley 1997; Kaiser et al. 2003; Konishi et al. 1999; Menon et al. 2001; Watanabe et al. 2002; Watanabe 1986; Weisbrod et al. 2000), others report parietal cortical involvement implicating a more distributed cortical network extending beyond 
frontal systems (Durston et al. 2002; Garavan et al. 1999; Watanabe et al. 2002).

Consistent with other measures of inhibitory control (de Wit 2009), NOGO P3 responses have been shown to be diminished in alcoholics (Ceballos et al. 2003; Cohen et al. 1997b; Ford et al. 1991; Hada et al. 2000; Kamarajan et al. 2005a; Rodriguez Holguin et al. 1999a) and in those with a predisposition to alcoholism (Cohen et al. 1997a; Hada et al. 2001; Kamarajan et al. 2005b; Rodriguez Holguin et al. 1999b). This effect has been hypothesized to be due to disruption of the neural circuit responsible for inhibitory processing (Kamarajan et al. 2005a).

The use of EEG time-frequency response analysis permits an assessment of the extent to which the low P3 in alcoholism can be accounted for by deficits in frequencyspecific oscillatory activity. It provides a measure of the activity in neural circuits that may be modulated in association with sensory and cognitive processing of stimuli and underlie the generation of evoked potential components (Basar et al. 2001). Previous studies using time-frequency analysis related to the $\mathrm{P} 3$ in response to target detection have found significant differences between alcoholics and controls (Andrew and Fein; Jones et al. 2006) or between at risk offspring of alcoholics and controls (Rangaswamy et al. 2007) with alcoholics or their offspring respectively having less $\delta$ and $\theta$ power than controls. A similar result was found in perhaps the only published study using time-frequency analyses of the NOGO P3 (Kamarajan et al. 2004). As reviewed by Rangaswamy et al. (2007), there is evidence from studies in normal individuals that supports the hypothesis that $\delta$ oscillations relate to processes such as signal detection and decision making and $\theta$ oscillations reflect activity within a fronto-limbic circuit thought to be involved in the generation of the P3 response. Oscillations in these frequency bands likely reflect the integration of information across different brain regions (von Stein and Sarnthein 2000).

Converging evidence from neuroimaging, EEG source localization and neuropsychological studies indicate that P3 is produced by the activation of a network of brain regions (Linden 2005) linked by white matter fiber systems. It is thus reasonable to hypothesize that the degradation of white matter typically seen in alcoholism (for reviews see Pfefferbaum and Sullivan 2010; Sullivan and Pfefferbaum 2005) will negatively affect the network properties, including the ability to produce oscillatory activity in the $\delta$ and $\theta$ bands.

Diffusion tensor imaging (DTI) can provide visual depictions of white matter fiber systems (Lehericy et al. 2004; Stieltjes et al. 2001; Xu et al. 2002), which can be measured with quantitative fiber tracking (Gerig et al. 2005; Sullivan et al. 2006), where DTI metrics such as fractional anisotropy (FA) and diffusivity are derived from focal fiber tracking. FA provides a measure of the extent to which diffusion of water molecules within the white matter tract is orientationally specific and linear rather than isotropic and random, as would be the case in cerebrospinal fluid (Sullivan and Pfefferbaum 2007). Diffusivity quantifies the magnitude of diffusion and can be decomposed into axial (longitudinal) diffusivity $(\lambda \mathrm{L})$, which can be altered with disruption of axonal integrity and axonal deletion and radial (transverse) diffusivity $(\lambda \mathrm{T})$, which increases selectively with decline in myelin integrity (Song et al. 2003; Song et al. 2002; Song et al. 2005; Sun et al. 2006a; Sun et al. 2006b).

Although there is an obvious basis for the hypothesis that synchronized EEG activity should be related to white matter integrity, few studies have been conducted to evaluate this relationship. To our knowledge, no study has been conducted to evaluate the role of degraded white matter in the damping of P3 responses in alcoholism or normal aging. The corpus callosum and cingulate bundles are white matter tracts of particular interest in this context given the previously observed effects of alcoholism on their FA and diffusivity (Pfefferbaum et al. 2010; Pfefferbaum et al. 2009) and their roles in providing inter-hemispheric (corpus callosum) and intra-hemispheric fronto-parietal (cingulate bundles) connectivity to support P3 generation. This paper thus seeks to evaluate the hypothesis that DTI measures of white matter fiber tract integrity in selective sectors of the corpus callosum and cingulate bundles are related to the $\delta$ and $\theta$ oscillatory activity underlying P3 generation in normal aging and alcoholism.

\section{Methods}

\section{Participants}

Included in this analysis were ten alcoholics with contemporaneously collected EEG and DTI data and 25 age- and sex-matched controls. Demographic, behavioral, and cognitive data were collected within 1 week of ERP collection and appear in Table 1. Of the ten alcoholics, seven had ERP and DTI examinations within 1 day of each other, and three had the two sessions 4,15 , and 17 days apart. Of the 25 controls, 16 had both examinations within 18 days, 4 had a 1 to 6 months lag, and three had about a year lag.

As per our standard laboratory practice (e.g., Pfefferbaum et al. 2007), men and women with alcoholism were recruited by referral from San Francisco Bay Area outpatient substance abuse treatment centers. Control subjects were recruited by referral from patient participants, by Internet posting, newspaper advertisements, flyers, and word of mouth. Referrals and inquiries were followed-up with a brief screening interview designed to identify subjects who would be ineligible for the study by virtue of a diagnosis of schizophrenia, bipolar disorder, neurological disease not 
Table 1 Group characteristics: mean $( \pm \mathrm{SD})$ or frequency count

\begin{tabular}{|c|c|c|c|}
\hline & Control & Alcoholic & $t$ test $p$ value \\
\hline Men, women & 12,13 & 5,5 & n.s. \\
\hline Age & $56.5(12.81)$ & $53.1(9.05)$ & n.s. \\
\hline Socioeconomic status (SES) ${ }^{\mathrm{a}}$ & $21.6(8.14)$ & $27.3(12.61)$ & n.s. \\
\hline Handedness ${ }^{\mathrm{b}}$ & $17.3(4.00)$ & $24.2(16.00)$ & 0.055 \\
\hline Body mass index & $25.3(4.27)$ & $30.5(6.78)$ & 0.0215 \\
\hline Lifetime alcohol consumption (kg) & $53.8(64.7)$ & $741(630.0)$ & 0.0001 \\
\hline NART IQ & $115.9(5.45)$ & $113.8(7.36)$ & n.s. \\
\hline Dementia rating scale ${ }^{c}$ & $139.9(3.47)$ & $139.8(139.8)$ & n.s. \\
\hline \multicolumn{4}{|l|}{ WASI } \\
\hline VIQ & $115(8.93)$ & $112.6(10.36)$ & n.s. \\
\hline PIQ & $121.6(12.59)$ & $108.9(15.48)$ & 0.017 \\
\hline FSIQ & $120.8(11.0)$ & $113.8(11.2)$ & n.s. \\
\hline \multicolumn{4}{|l|}{ WMS-R } \\
\hline General memory index & $121.1(13.04)$ & $123(12.62)$ & n.s. \\
\hline Attention index & $110.2(11.08)$ & $108.5(19.23)$ & n.s. \\
\hline
\end{tabular}

The NART score is an estimated premorbid IQ from the National Adult Reading Test (Nelson 1982). The WASI is the Wechsler Abbreviated Scale of Intelligence (Wechsler 1999), which provides estimates of Verbal (VIQ), performance (PIQ), and full-scale (FIQ) intelligence. The WMS-R is the revised version of the Wechsler Memory Scale (Wechsler 1997)

${ }^{a}$ Lower scores indicate higher SES (Hollingshead and Redlich 1958)

${ }^{\mathrm{b}}$ Right handedness $=14-32$; left handedness $=50-70$ (Crovitz and Zener 1962)

${ }^{\mathrm{c}}$ Dementia cut-off $<124$; no one scored at or below this cut-off (Mattis 1988)

related to alcohol use, or inability to undergo MRI. Those who met initial criteria were invited for a detailed assessment in our laboratory, where they also provided written informed consent for study.

\section{Clinical evaluation}

All alcoholics and controls underwent a series of structured interviews to characterize alcohol history and other pertinent medical and psychiatric information. Clinical psychologists administered the Structured Clinical Interview for DSM-IV (First et al. 1994) to identify study volunteers who met criteria for alcohol dependence or abuse, to exclude subjects who met lifetime criteria for schizophrenia or bipolar disorder or for non-alcohol substance dependence or abuse within the prior 3 months, and to confirm that prospective controls did not meet DSM-IV criteria for any Axis I disorder. History of alcohol consumption (Pfefferbaum et al. 1992; Skinner 1982; Skinner and Sheu 1982), yielding quantitative lifetime consumption of alcohol, revealed that the alcoholics drank about 13 times as much as the controls. The alcoholics were abstinent from alcohol for about 1 year on average (range 2 days to 2.5 years).

Relative to controls, alcoholics displayed a non-significant trend $(p=0.055)$ to be more likely to be right handed (Crovitz and Zener 1962), had a higher ( $p=.025)$ body mass index (height $\mathrm{cm} /$ weight $\mathrm{kg}^{2}$, an index of nutritional status), and a lower $(p=.017)$ performance intelligence quotient (IQ) derived from the Wechsler Abbreviated Scale of Intelligence (WASI) (Wechsler 1997) than controls. They did not differ on measures of verbal or full-scale IQ (Wechsler 1997) or memory derived from the revised version of the Wechsler Memory Scale (Wechsler 1999), but were of slightly lower socioeconomic status (SES) (Hollingshead and Redlich 1958) and had modestly lower premorbid IQ, estimated with the National Adult Reading Test (Nelson 1982). Both groups performed well on the Mattis Dementia Rating Scale (Mattis 1988), and no subject fell below the dementia cut-off. Descriptive statistics of these variables appear in Table 1

ERP task: stimulus presentation

Visual stimuli were presented on a Dell 18" flat panel monitor, driven by an nVidia, GeForce FX5200 DVI graphics card. Subjects were presented with an "oddball" Bernoulli series of letters delivered at $1 \mathrm{~s}$ intervals. The letters were presented in the center of the screen and subtended $5^{\circ}$ of visual angle. The frequently occurring letter "X" occurred with a probability of $88 \%$, with the infrequent letter $\mathrm{K}$ making up the remaining $12 \%$ of stimuli. In the first presentation (GO), the infrequent letter "K" was designated as the target to which subjects were instructed to press a reaction time (RT) key with the index finger of the preferred hand. In the second presentation 
(NOGO), subjects were asked to press the RT button to the frequent (non-target) stimuli (Letter $\mathrm{X}$ ) and not to respond to the letter K. Stimulus presentation was controlled using Neuroscan (Charlotte, NC) STIM software.

\section{EEG data collection}

EEG data were collected from sites FP1, FP2, Fz, Cz, Pz, $\mathrm{O} 1$, and $\mathrm{O} 2$ using Grass $10 \mathrm{~mm}$ gold cup electrodes and referenced to linked ears. Vertical (above and below left eye) and horizontal (bilateral outer canthi) EOG derivations were also recorded. All signals were collected using a Neuroscan Synamps amplifier and Neuroscan (Charlotte, NC, USA) SCAN 4.3 software. Data were collected with wide bandpass settings $(0.1$ to $200 \mathrm{~Hz}$ ) with a sampling rate of $1,000 \mathrm{~Hz}$ and stored as a continuous file for each of the GO and NOGO conditions.

\section{EEG time-voltage analysis}

Continuous EEG data were low-pass filtered with a $12 \mathrm{~Hz}$ zero phase filter. ERP epochs were time-locked to the onset of the " $\mathrm{K}$ " in the GO condition, including a $100 \mathrm{~ms}$ baseline preceding the stimulus and $900 \mathrm{~ms}$ after it. Trials with no responses (that is errors) were excluded. In the NOGO condition, equivalent $1,000 \mathrm{~ms}$ epochs were timelocked to the onset of the " $\mathrm{K}$ " and trials with a false alarm response (errors) were excluded. EOG activity such as saccades and blinks were corrected using a regressionbased method (Gratton et al. 1983) before baseline correcting by subtracting the average of the $100-\mathrm{ms}$ period before $\mathrm{K}$ onset from every sample in the epoch. Individual trials were rejected if any artifacts $( \pm 100 \mu \mathrm{V}$ values $)$ existed in $\mathrm{Fz}, \mathrm{Cz}$, or Pz. P3 was identified as the positive peak between 250 and $600 \mathrm{~ms}$ at $\mathrm{Pz}$ for each subject in the GO condition and $\mathrm{Cz}$ for each subject in the NOGO condition, with manual adjustment of the peak locations as necessary. These peak latencies defined the $50 \mathrm{~ms}$ search window ( $\pm 25 \mathrm{~ms}$ ) for the other sites in each condition. Amplitude values were calculated as the average area around the peak $( \pm 25 \mathrm{~ms})$, measured relative to the average voltage in the 100 ms pre-stimulus baseline at $\mathrm{Fz}, \mathrm{Cz}$, and $\mathrm{Pz}$.

\section{EEG time-frequency analyses}

Continuous EEG data were high-pass filtered with a $1 \mathrm{~Hz}$ zero phase filter. Additional processing steps were identical to those in the ERP analysis above with two differences. Epochs were $5 \mathrm{~s}$ in length $(2 \mathrm{~s}$ preceding the $\mathrm{K}$ onset and $3 \mathrm{~s}$ following it) to facilitate wavelet processing of lowfrequency activity and trials were rejected for artifacts outside of a smaller range $( \pm 75 \mu \mathrm{V})$. The time-frequency analysis was done with a Morlet wavelet decomposition
(Tallon-Baudry et al. 1997) using FieldTrip software (http:// fieldtrip.fcdonders.nl/). Its Gaussian shape was defined by a constant ratio $\left(\sigma_{f}=f / 7\right)$ and wavelet duration $\left(6 \sigma_{t}\right)$, where $f$ was the center frequency and $\sigma_{t}=1 /\left(2 \pi \sigma_{f}\right)$. Typical wavelet decompositions convolve the EEG signal with complex wavelets for all frequencies of interest, moving sample-bysample in the time domain. FieldTrip achieves the same result by multiplying the Fast Fourier Transform (FFT) of the wavelet by the FFT of the EEG signal. The inverse FFT of the resultant is then adjusted so that the time course of the data corresponds to the time course of the original signal. This series of calculations progressed in $1 \mathrm{~Hz}$ steps in the frequency domain and was equivalent (Lyons 2004) and computationally more efficient than convolution in the time domain.

After applying this method to every trial for the frequencies between 3 and $7 \mathrm{~Hz}$ at $\mathrm{Fz}, \mathrm{Cz}$, and $\mathrm{Pz}$, the phase-locking factor was calculated as 1 minus the phase variance. This calculation is identical to that used by others (Ford et al. 2008; Tallon-Baudry et al. 1997). High phaselocking at a specific frequency and within a specific time window indicates that oscillations have become phasesynchronized across trials with respect to event onset.

In addition, total power was calculated for each individual trial and for each frequency and time point; complex results of the wavelet decomposition were squared. We extracted mean total power values for the baseline periods from each condition for all subjects. Comparing these values between groups revealed no group differences. Values from each time and frequency point were baseline ( -100 to $0 \mathrm{~ms}$ ) corrected by dividing that point by the average of the data points in the baseline interval for that frequency. The resulting power quotient was then $10 \times \log 10$ transformed, returning values on a decibel $(\mathrm{dB})$ scale because of the logarithmic correction for the baseline.

The phase-locking factor and total power values that were entered into the statistical analysis were extracted for each frequency of interest $(\delta=3 \mathrm{~Hz} ; \theta=4-7 \mathrm{~Hz})$ over a $50 \mathrm{~ms}$ window centered on each individual subject's P3 peak latency. However, it is important to note the varying temporal window of the wavelet approach. Specifically, time-frequency data extracted $50 \mathrm{~ms}$ surrounding the P3 peak result from convolution with a wavelet that spans $6 \sigma_{t}$ milliseconds of EEG data for each sample in the $50 \mathrm{~ms}$ extraction window. For example, $5 \mathrm{~Hz}$ activity for a subject with a P3 peak latency of $300 \mathrm{~ms}$ is estimated using data points that end at $325+3 \sigma_{t} \mathrm{~ms}(\sim 925 \mathrm{~ms}$ at the $5 \mathrm{~Hz}$ frequency). These points are weighted by a Gaussian window centered on the sample of interest $(300 \mathrm{~ms}$ in this case), but in every frequency, data sampled outside the $50 \mathrm{~ms}$ extraction window contribute to the calculation. This P3-locked, $50 \mathrm{~ms}$ extraction window was used to best 
emphasize the time-frequency dynamics at the moment of the ERP peak.

\section{MRI acquisition and processing}

MRI and DTI acquisition and analysis protocols were described previously (Pfefferbaum et al. 2007; Pfefferbaum et al. 2009). Imaging was performed on a $1.5 \mathrm{~T}$ GE clinical whole body system. A dual-echo fast spin-echo (FSE) coronal structural sequence was acquired (47 contiguous, 4$\mathrm{mm}$ thick slices; TR/TE1/TE2 $=7,500 / 14 / 98 \mathrm{~ms}$; matrix $=256 \times 192$ ). DTI was performed with the same slice location parameters as the dual-echo FSE, using a single shot spin-echo echo-planar imaging technique (47 contiguous, 4-mm thick slices, $\mathrm{TR} / \mathrm{TE}=10,000 / 103 \mathrm{~ms}$, matrix $=128 \times 128$, in-plane resolution $=1.875 \mathrm{~mm}^{2}, b$ value $=860 \mathrm{~s} / \mathrm{mm}^{2}$ ). Diffusion was measured along six non-collinear directions (six NEX) with alternating signs to minimize the need to account for cross-terms between imaging and diffusion gradients (Neeman et al. 1991). For each slice, six images with no diffusion weighting $\left(b=0 \mathrm{~s} / \mathrm{mm}^{2}\right)$ were also acquired.

\section{Image processing}

The structural data were passed through the FSL Brain Extraction Tool (Smith 2002) to extract the brain. Eddy current-induced image distortions in the diffusion-weighted images for each direction were minimized by alignment with an average made of all 12 diffusion-weighted images using a 2-D six-parameter affine correction on a slice-by-slice basis (Woods et al. 1998). The DTI data were then aligned using the FSE data by a non-linear 3D warp (third-order polynomial), which provided in-plane and through-plane alignment. On a voxel-by-voxel basis, fractional anisotropy and apparent diffusion coefficient, the latter decomposed into its longitudinal and $\left(\lambda \mathrm{L}=\lambda_{1}\right)$ and transverse $\left(\lambda \mathrm{T}=\left[\lambda_{2}+\lambda_{3}\right] / 2\right)$ diffusivity components, were computed. FA ranged from 0 to 1 , and diffusivity was expressed in units of $10^{-6} \mathrm{~mm}^{2} / \mathrm{s}$.

\section{Warping to common coordinates}

To achieve common anatomical coordinates across subjects, a population-average FA template (Sullivan et al. 2010a) was constructed from the FA data of 120 control subjects (20-81 years old) with group-wise affine registration (Learned-Miller 2006) followed by iterative nonrigid averaging (Rohlfing and Maurer 2003). Each subject's FA data set was registered to the population FA template with a nine-parameter affine transformation followed by nonrigid alignment using a multi-level, third-order B-spline, with 5$\mathrm{mm}$ final control point spacing (Rohlfing and Maurer 2003; Rueckert et al. 1999).
Fiber tracking ROI identification

Landmarks were identified in three dimensions on the laboratory grand average FA image in common space (Rohlfing et al. 2010). The genu and splenium were identified in the midline at the center of their maximum extent and the left and right superior cingulate bundles at the level of the anterior margin of pons. Each landmark was dilated with a morphological operator to produce a cube as the fiber tracking target. Sources were defined as planes anterior and posterior to the superior cingulate, a perpendicular midline plane anterior to the genu and a similar plane posterior to the splenium. The targets and sources in common space were then transformed into each subject's native space for fiber tracking (left panel of Fig. 3).

The fiber tracking was performed on native, unwarped DTI data for each of the regions of interest separately, using software distributed by Gerig et al. (2005) based on the method of Mori and colleagues (Mori and van Zijl 2002; Xu et al. 2002; Xue et al. 1999). Tracking parameters included white matter extraction threshold (minimum FA) of 0.17 , fiber tracking threshold of 0.125 , and maximum voxel-tovoxel coherence minimum transition smoothness threshold of 0.80 ( $\sim 37^{\circ}$ maximum deviation between voxels), with no limit on the number of fibers. The mean FA, $\lambda \mathrm{L}$, and $\lambda \mathrm{T}$ of each voxel comprising each fiber, for all fibers, were determined for the left and right cingulate bundles and for the genu and splenium of the corpus callosum.

\section{Statistical analysis}

Within each of the GO and NOGO conditions, P3 peak and P3 latency measures at $\mathrm{Fz}, \mathrm{Cz}$, and $\mathrm{Pz}$ were entered into a MANCOVA model using age as a covariate and diagnosis as the between groups factor. When an overall MANCOVA model showed significant effect of diagnosis, the relevant univariate ANCOVA values were then evaluated for each dependent variable. Time-frequency analysis data were then evaluated at sites $(\mathrm{Fz}, \mathrm{Cz}$, or $\mathrm{Pz})$ showing significant diagnosis or age effects for P3 amplitude or latency. This was accomplished using ANCOVA models with diagnosis as a between groups factor and age as a covariate for variables showing significant effects of diagnosis. Bivariate relations were tested with Pearson correlations. Stepwise multiple regression using age and the time-frequency analysis measures for variables showing significant effects of age. Finally, time-frequency variables significantly associated with age or diagnosis were evaluated with bivariate and stepwise multiple regression, using age, $\mathrm{BMI}, \mathrm{FA}$, and diffusivity measures $(\lambda \mathrm{T}$ and $\lambda \mathrm{L}$ ) from the cingulate bundles (left and right cingulate bundles were averaged) and from the genu and splenium of the corpus callosum to determine the relations of white matter integrity to indices of EEG. 


\section{Results}

\section{NOGO condition}

The MANCOVA model for P3 amplitudes and latencies at $\mathrm{Fz}, \mathrm{Cz}$, and $\mathrm{Pz}$ in the NOGO condition showed a significant effect of diagnosis $(F(6,25)=3.12, p=0.020)$. The univariate models showed alcoholics to have smaller P3 amplitude at $\mathrm{Cz}$ than controls $(F(1,30)=4.73, p=0.038$; Fig. 1$)$.

Univariate ANCOVA models revealed that relative to controls alcoholics had significantly lower $\mathrm{Cz} \delta$ total power $(F(1,30)=13.61, p=0.002$; Fig. 2$) . \mathrm{Cz} \delta$ total power was significantly correlated with $\mathrm{P} 3$ amplitude at $\mathrm{Cz}(r=$ $0.332, p=0.030$ ). Stepwise multiple regression analysis to evaluate the relations between $\mathrm{Cz} \delta$ total power and regional DTI measures indicated lower $\delta$ power correlated with higher $\lambda \mathrm{T}$ in the cingulate bundle $(r=-0.473, p=$ 0.006 , right panel of Fig. 3) Exploration of values from the left and right cingulate bundles separately revealed significant correlations between $\mathrm{Cz} \delta$ total and $\lambda \mathrm{T}$ in both the left $(r=-0.439, p=0.006)$ and the right $(r=-0.470, p=$ 0.003 ) bundles.

GO condition

The MANCOVA model for the GO condition showed a significant effect of age $(F(6,26)=6.53, p<0.001)$ but not diagnosis (Fig. 1). Univariate ANCOVA models showed age to be significantly related to $\mathrm{P} 3$ latency at $\mathrm{Fz}(F(1,31)=22.32$, $p<0.001), \mathrm{Cz}(F(1,31)=26.81, p<0.001)$, and $\mathrm{Pz}(F(1,31)=$ $20.85, p<0.001)$ and on $\mathrm{P} 3$ amplitude at $\mathrm{Fz}(F(1,31)=19.07$, $p<0.001)$ and $\mathrm{Cz}(F(1,31)=4.59, p=0.040)$. Neither total
GO
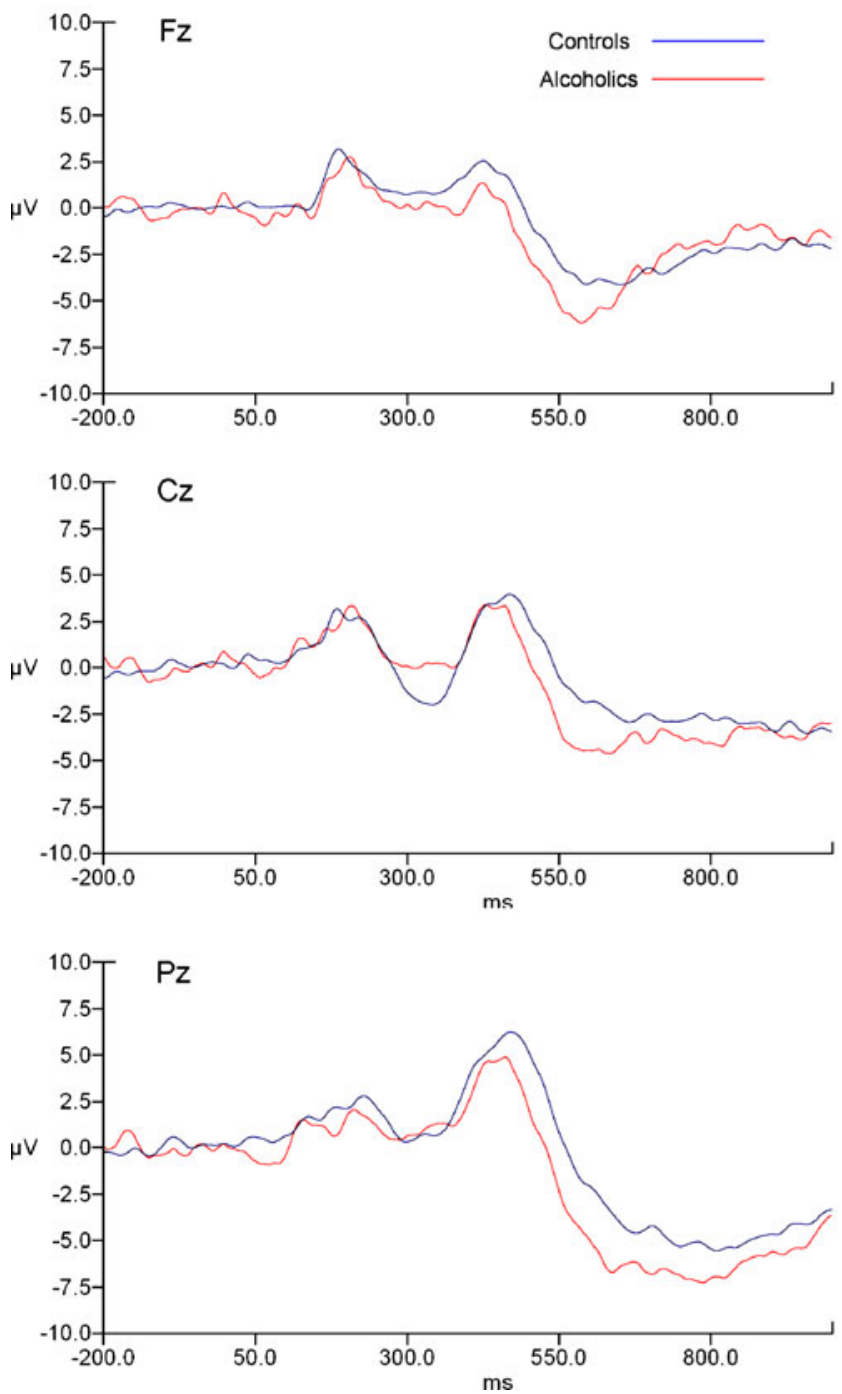

NOGO
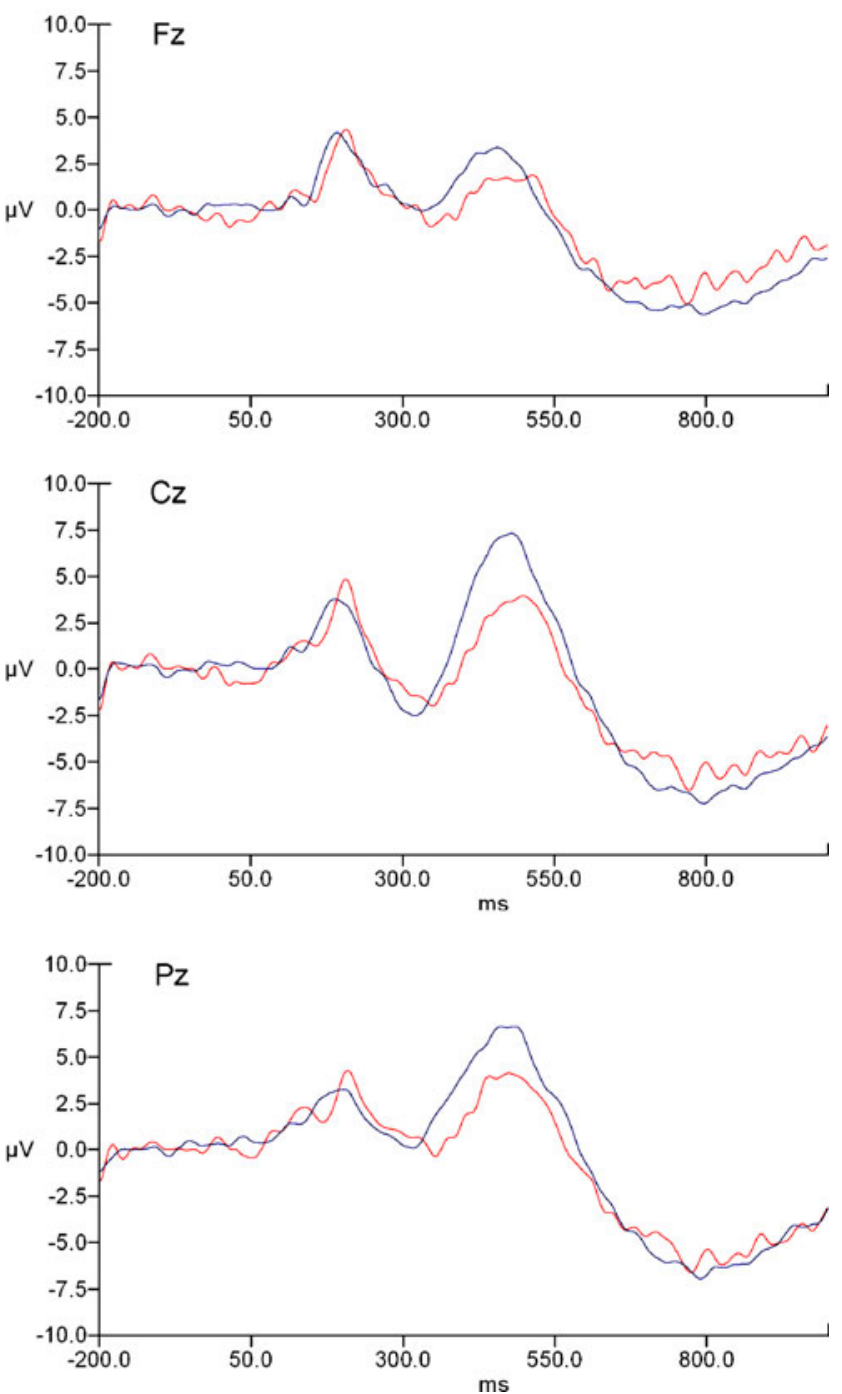

Fig. 1 Grand mean averaged evoked responses from the time-voltage analysis from the GO (left panel) and NOGO (right panel) conditions. Data are presented for the $\mathrm{Fz}, \mathrm{Cz}$, and $\mathrm{Pz}$ sites for alcoholic (red) and control (blue) subjects 


\section{Total Power}

\section{Healthy Controls}
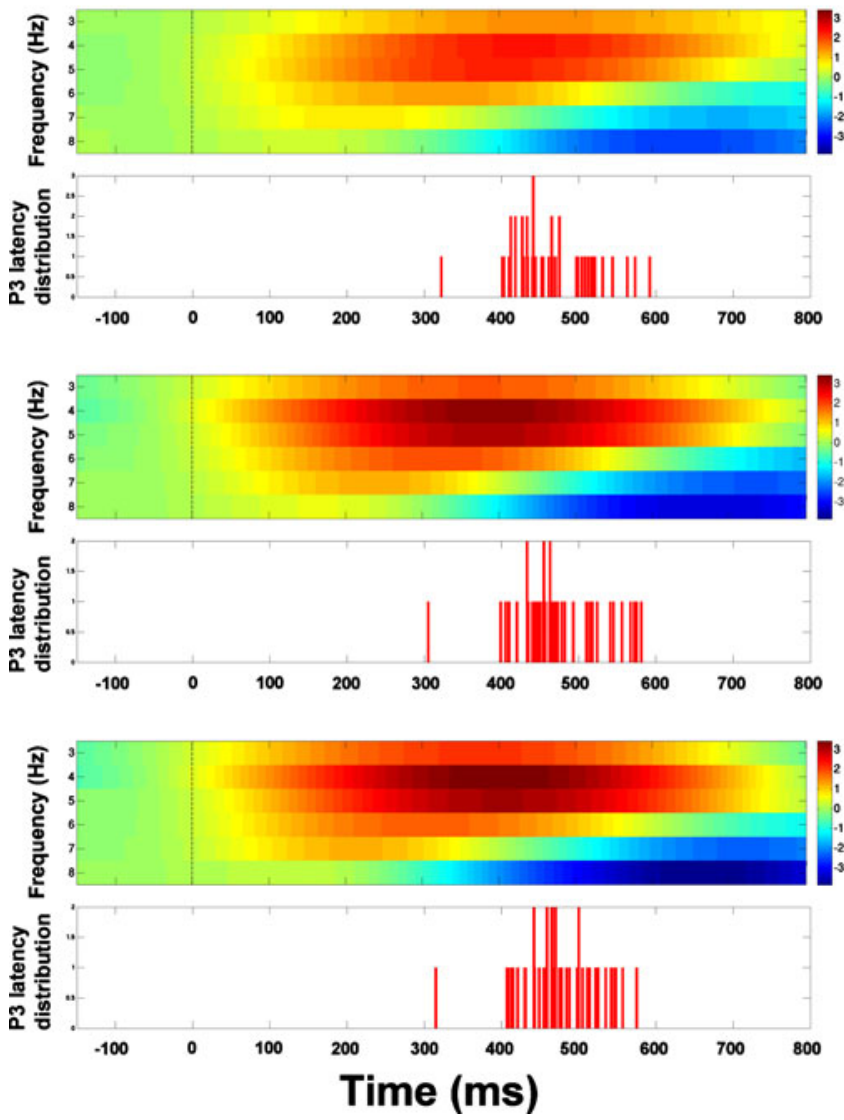

Fig. 2 Total power plots or the NOGO condition, from control (left) and alcoholics (right) subjects from $\mathrm{Fz}, \mathrm{Cz}$, and Pz. EEG frequency is indicated on the $y$-axis and spans 0 to $50 \mathrm{~Hz}$. Time is indicated on the $x$-axis and spans -100 to $800 \mathrm{~ms}$. The visual stimulus occurred at $0 \mathrm{~ms}$. Higher levels of total power in the $50 \mathrm{~ms}$ window around the P3 peak, is shown in hot colors, as indicated on the color scale located to the far right of each plot. Total power data are

power (Fig. 2) nor phase-locking factor for the $\delta$ or $\theta$ bands showed age or diagnosis effects at Fz, Cz, or Pz.

\section{Discussion}

The data presented are from a small number of subjects and thus should be interpreted cautiously. Factors that may well prove to be important in modulating the reported relationships such as sex and length of sobriety in the alcoholics were not able to be evaluated in the present study given the small numbers and the low statistical power.

Nonetheless, the results highlight the sensitivity of the NOGO P3 to the negative effects of alcoholism, with the NOGO P3 amplitude significantly smaller in alcoholics than controls at $\mathrm{Cz}$, the site at which it is optimally recorded (Fallgatter et al. 1997). Wavelet-based time-frequency
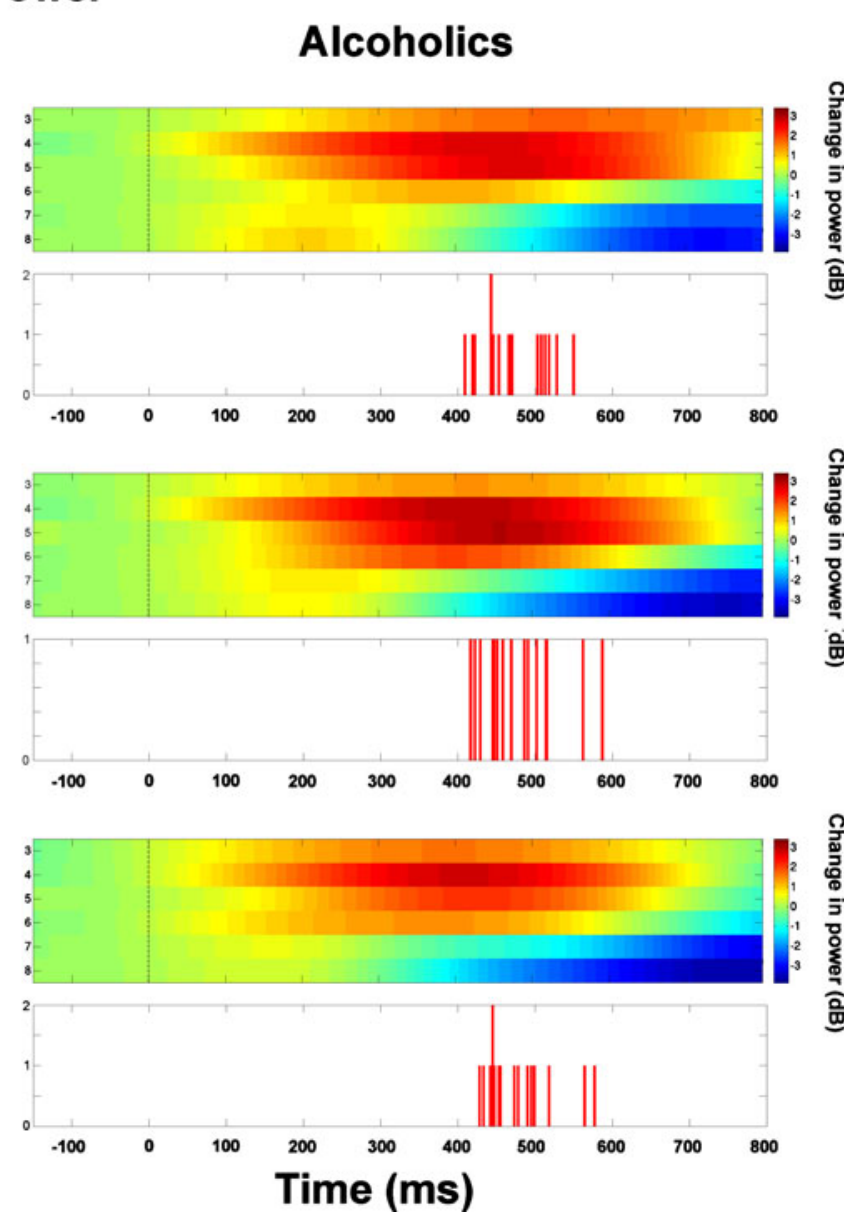

displayed on a $\mathrm{dB}$ scale, which represents relative change in power as defined by: Total power pof $_{t, f}=10 \times \log _{10}\left(\frac{\text { power }_{t, f}}{\operatorname{mean}\left(\text { power }_{-100 \text { to } 0 \mathrm{~ms}, f}\right)}\right)$. Where $t=$ data point in $\mathrm{ms} ; f=$ frequency in Hz. The histogram displayed under each frequency plot displays the frequency distribution of P3 latencies for the subjects contributing to the averaged data

analysis of the time interval surrounding the $\mathrm{P} 3$ peak at $\mathrm{Cz}$ revealed that total $\delta$ power was smaller in alcoholics than controls and significantly related to transverse diffusivity in the cingulate bundles. Although $\mathrm{P} 3$ in the GO condition did not differentiate alcoholics from controls, P3 amplitude was smaller and P3 latency longer with older age in the combined samples. Reduced P3 amplitude is a robust finding in alcoholics and those at risk for alcoholism (see Porjesz and Begleiter (2003) and Porjesz et al. (2005) for reviews). Most studies have focused on the P3 component associated with correct determination of a previously identified target stimulus in an oddball paradigm. However, the smaller NOGO P3 in alcoholics compared to controls is consistent with previous studies (Ceballos et al. 2003; Cohen et al. 1997b; Ford et al. 1991; Hada et al. 2000; Kamarajan et al. 2005a; Oddy and Barry 2009; Rodriguez Holguin et al. 1999a). Indeed the identified sensitivity of P3 from the GO/ 

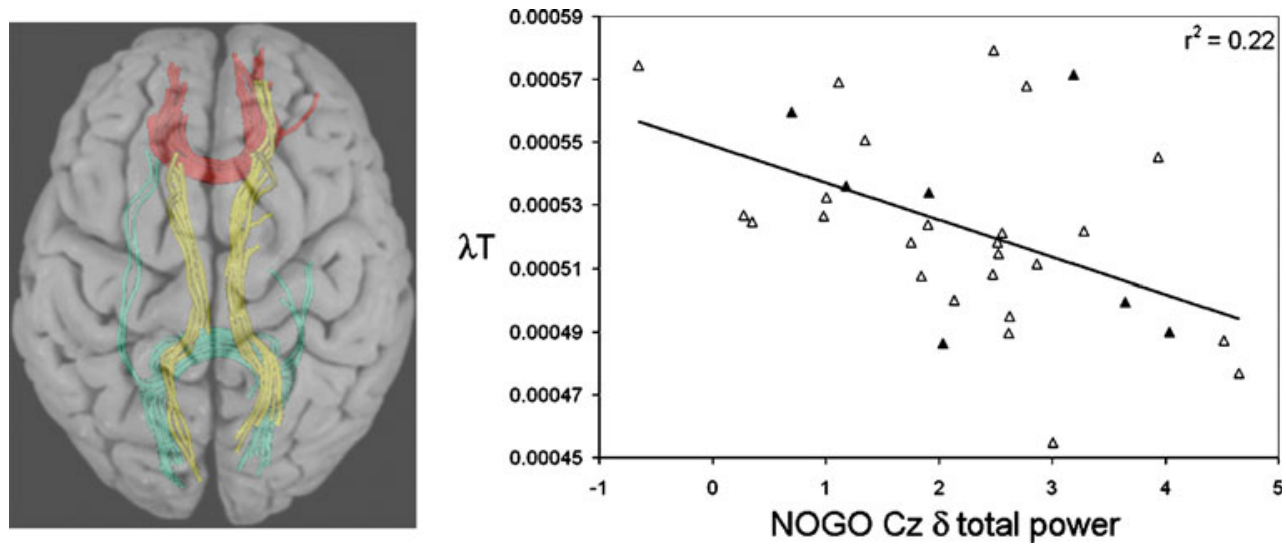

Fig. 3 Left panel representation of identified fiber tracts for the genu (red) and splenium (green) of the corpus callosum and the left and right cingulate bundles (yellow) superimposed on a "glass brain". Right panel the relationships between NOGO $\mathrm{Cz}$ total $\delta$ power and

NOGO to alcoholism led Kamarajan and colleagues (Kamarajan et al. 2005a) to deem the P3 elicited in the NOGO paradigm as "the electrophysiological signature of response inhibition" and an endophenotypic marker of alcoholism.

The attenuated $\delta$ power measures in alcoholics are also consistent with previous studies of the visual P3 to target stimuli using different but analogous time-frequency analysis techniques. In all three studies, significant differences between alcoholics and controls were limited to the $\delta$ and $\theta$ bands. Jones et al. (2006) reported that evoked and total $\delta$ and $\theta$ total power were lower in alcoholics than controls. Rangaswamy et al. (2007) reported that the offspring of alcoholics had lower evoked and total $\delta$ power and lower $\theta$ total power when compared with controls. More recently, Andrew and Fein (2010) reported that alcoholics had lower evoked and total $\delta$ power and lower $\theta$ total power than controls. To our knowledge, time-frequency analysis has only once been used to compare EEG between alcoholics and control in the context of a GO/NOGO task using a matching pursuit approach to signal decomposition that provides a measure similar to total power (Kamarajan et al. 2004). They reported that $\delta$ power was lower in alcoholics in both the GO and NOGO conditions, with the effects larger in the NOGO than GO condition and widespread over a range of scalp sites. $\theta$ power was smaller only in the NOGO condition and then only at frontal sites. The present data did not replicate the previous findings of lower $\theta$ power in alcoholics than controls (Andrew and Fein; Jones et al. 2006; Kamarajan et al. 2004). One possible explanation relates to the P3-locked search window used in the present analysis. Because alcoholics tend to have later P3 peaks, using a window that varies according to that latency ensures that group comparisons will only capture $\theta$ power specifically related to $\mathrm{P} 3$ amplitude. Previous studies may have included $\theta$ transverse diffusivity in the left and right cingulate bundles. Relationships are presented for all subjects combined. Alcoholics (filled symbols) and control (open symbols) subjects are visually distinguished for purposes of illustration only

power related to other earlier components. However, the most likely explanation for the lack of a $\theta$ power group difference is the low statistical power associated with the small number of alcoholic subjects relative to the previous studies.

An earlier application of the present wavelet-based timefrequency analysis (Ford et al. 2008) revealed differences in P3 amplitude between schizophrenic and control samples with associated lower $\delta$ total power. The low P3 amplitude in the alcoholics of the present study, however, was not associated with a reduction in cross trial phase synchrony (phase-locking factor) at $\delta$ or $\theta$ frequencies as was the case with the reduced P3 in schizophrenics (Ford et al. 2008). Differences in task characteristics and in stimulus modality confound the diagnostic differences and make direct comparison challenging. Further, the small sample size leaves open the possibility that the study may have been underpowered to detect alcoholic-control differences. Nonetheless, the lack of a difference in phase-locking factor between alcoholics and controls is of note. Smaller $\delta$ total power in association with the $\mathrm{P} 3$ peak in alcoholics in the absence of a phase-locking factor difference implies that $\delta$ oscillations are intact in alcoholics, but that relative to controls, they have dampened inhibitory processing-related modulation of the magnitude of the response

There is a robust postmortem literature showing that constituents of white matter fiber systems are negatively affected by alcoholism (De la Monte 1988; Harper et al. 2003; Harper et al. 1990) and normal aging (Aboitiz et al. 1996; Dickson et al. 1992; Kemper 1994; Marner et al. 2003; Meier-Ruge et al. 1992) Both alcoholism (Lewohl et al. 2000; Tarnowska-Dziduszko et al. 1995) and aging (Peters 2002) show demyelination. In vivo DTI studies of alcoholism (Rosenbloom et al. 2003; Sullivan and Pfefferbaum 2005) and aging (Salat et al. 2005; Stadlbauer et al. 2008; Sullivan and Pfefferbaum 2006; 2007; Sullivan et al. 2010b) 
comport with the postmortem findings in demonstrating low FA and high diffusivity, typically $\lambda \mathrm{T}$, a marker of myelin degradation (Song et al. 2003; Song et al. 2002; Song et al. 2005). The relation between low $\delta$ power and high $\lambda \mathrm{T}$ in cingulate bundles in the present analysis suggests myelin degradation in the long association fiber system of the cingulate bundle as underlying low $\delta$ power in alcoholism and older age.

While few studies have been conducted relating EEG or ERPs to DTI measures, those that have been published have shown promise in informing EEG-white matter relationships. For example, Westlye et al. (2009) reported a significant relationship between transverse diffusivity $(\lambda \mathrm{T})$ in the cingulate bundle and the amplitude of the error-related negativity, thought to be generated in the anterior cingulate. Valdes-Hernandez et al. (2010) also recently reported relationships between FA in posterior white matter (superior and posterior corona radiata and posterior corpus callosum) and the $\alpha$ frequency EEG activity. Herein, the significant regression relations between $\delta$ total power at $\mathrm{Cz}$ and transverse diffusivity in the left and right cingulate bundles can be interpreted as implicating white matter degradation, and myelin status in particular, with damped NOGO P3 generation in alcoholism and older age (Fjell and Walhovd 2004; Stige et al. 2007; Vallesi et al. 2009).

It is likely that NOGO P3 generation involves activation of a network of brain regions associated with inhibitory behavior. $\theta$ frequency oscillations in the EEG have been shown to relate to long-range synchronization (e.g., frontoparietal) systems as opposed to higher frequencies that appear to reflect short-range networks (von Stein and Sarnthein 2000). There is further evidence to suggest that large networks can be recruited during slower frequency activity (Buzsaki and Draguhn 2004), which is consistent with our finding that $\delta$ total power related to measures of white matter microstructural integrity in pathways, including the cingulate bundles, linking frontal to parietal cortical regions.

Acknowledgment This work was supported by NIH grants AA012388, AA005965, AA014211, AG017919, and AA017168.

Open Access This article is distributed under the terms of the Creative Commons Attribution Noncommercial License which permits any noncommercial use, distribution, and reproduction in any medium, provided the original author(s) and source are credited.

\section{References}

Aboitiz F, Rodriguez E, Olivares R, Zaidel E (1996) Age-related changes in fibre composition of the human corpus callosum: sex differences. NeuroReport 7:1761-1764
Andrew C, Fein G (2010) Event-related oscillations versus eventrelated potentials in a P300 task as biomarkers for alcoholism. Alcohol Clin Exp Res 34:669-680

Barkley RA (1997) Behavioral inhibition, sustained attention, and executive functions: constructing a unifying theory of ADHD. Psychol Bull 121:65-94

Basar E, Schurmann M, Demiralp T, Basar-Eroglu C, Ademoglu A (2001) Event-related oscillations are 'real brain responses'wavelet analysis and new strategies. Int J Psychophysiol 39:91-127

Buzsaki G, Draguhn A (2004) Neuronal oscillations in cortical networks. Science 304:1926-9

Ceballos NA, Nixon SJ, Tivis R (2003) Substance abuse-related P300 differences in response to an implicit memory task. Prog Neuropsychopharmacol Biol Psychiatry 27:157-64

Cohen HL, Porjesz B, Begleiter H, Wang W (1997a) Neuroelectric correlates of response production and inhibition in individuals at risk to develop alcoholism. Biol Psychiatry 42:57-67

Cohen HL, Porjesz B, Begleiter H, Wang W (1997b) Neurophysiological correlates of response production and inhibition in alcoholics. Alcohol Clin Exp Res 21:1398-406

Crews FT, Boettiger CA (2009) Impulsivity, frontal lobes and risk for addiction. Pharmacol Biochem Behav 93:237-47

Crovitz HF, Zener KA (1962) Group test for assessing hand and eye dominance. Am J Psychol 75:271-276

De la Monte SM (1988) Disproportionate atrophy of cerebral white matter in chronic alcoholics. Arch Neurol 45:990-992

de Wit H (2009) Impulsivity as a determinant and consequence of drug use: a review of underlying processes. Addict Biol 14:22-31

Dickson DW, Crystal HA, Mattiace LA, Masur DM, Blau AD, Davies P, Yen SH, Aronson MK (1992) Identification of normal and pathological aging in prospectively studied nondemented elderly humans. Neurobiol Aging 13:179-89

Durston S, Thomas KM, Worden MS, Yang Y, Casey BJ (2002) The effect of preceding context on inhibition: an event-related fMRI study. Neuroimage 16:449-53

Fallgatter AJ, Brandeis D, Strik WK (1997) A robust assessment of the NoGo-anteriorisation of P300 microstates in a cued continuous performance test. Brain Topogr 9:295-302

First MB, Spitzer RL, Gibbon M, Williams JBW (1994) Structured clinical interview for Axis I DSM IV disorders. New York State Psychiatric Institute., New York State Psychiatric Institute

Fjell AM, Walhovd KB (2004) Life-span changes in P3a. Psychophysiology 41:575-83

Ford JM, Rosenbloom MJ, Sullivan EV, Pfefferbaum A (1991) ERPs and brain structure: relationships across the adult age span in alcoholics and in a patient with herpes simplex encephalitis. Electroencephalogr Clin Neurophysiol Suppl 42:342-54

Ford JM, Roach BJ, Hoffman RS, Mathalon DH (2008) The dependence of P300 amplitude on gamma synchrony breaks down in schizophrenia. Brain Res 1235:133-42

Fox HC, Hong KA, Sinha R (2008) Difficulties in emotion regulation and impulse control in recently abstinent alcoholics compared with social drinkers. Addict Behav 33:388-94

Garavan H, Ross TJ, Stein EA (1999) Right hemispheric dominance of inhibitory control: an event-related functional MRI study. Proc Natl Acad Sci U S A 96:8301-6

Gerig G, Corouge I, Vachet C, Krishnan KR, MacFall JR (2005) Quantitative analysis of diffusion properties of white matter fiber tracts: a validation study 13th Proceedings of the International Society for Magnetic Resonance in Medicine, Miami, FL, pp Abstract no. 1337

Gratton G, Coles MG, Donchin E (1983) A new method for off-line removal of ocular artifact. Electroencephalogr Clin Neurophysiol 55:468-84

Hada M, Porjesz B, Begleiter H, Polich J (2000) Auditory P3a assessment of male alcoholics. Biol Psychiatry 48:276-86 
Hada M, Porjesz B, Chorlian DB, Begleiter H, Polich J (2001) Auditory P3a deficits in male subjects at high risk for alcoholism. Biol Psychiatry 49:726-38

Harper CG, Smith NA, Kril JJ (1990) The effects of alcohol on the female brain - a neuropathological study. Alcohol Alcohol 25:445-448

Harper C, Dixon G, Sheedy D, Garrick T (2003) Neuropathological alterations in alcoholic brains. Studies arising from the New South Wales Tissue Resource Centre. Prog Neuropsychopharmacol Biol Psychiatry 27:951-61

Hollingshead A, Redlich F (1958) Social class and mental illness. Wiley, New York

Jones KA, Porjesz B, Chorlian D, Rangaswamy M, Kamarajan C, Padmanabhapillai A, Stimus A, Begleiter H (2006) S-transform time-frequency analysis of P300 reveals deficits in individuals diagnosed with alcoholism. Clin Neurophysiol 117:2128-43

Kaiser S, Unger J, Kiefer M, Markela J, Mundt C, Weisbrod M (2003) Executive control deficit in depression: event-related potentials in a Go/Nogo task. Psychiatry Res 122:169-84

Kamarajan C, Porjesz B, Jones KA, Choi K, Chorlian DB, Padmanabhapillai A, Rangaswamy M, Stimus AT, Begleiter $\mathrm{H}$ (2004) The role of brain oscillations as functional correlates of cognitive systems: a study of frontal inhibitory control in alcoholism. Int J Psychophysiol 51:155-80

Kamarajan C, Porjesz B, Jones KA, Choi K, Chorlian DB, Padmanabhapillai A, Rangaswamy M, Stimus AT, Begleiter H (2005a) Alcoholism is a disinhibitory disorder: neurophysiological evidence from a Go/No-Go task. Biol Psychol 69:353-73

Kamarajan C, Porjesz B, Jones KA, Chorlian DB, Padmanabhapillai A, Rangaswamy M, Stimus AT, Begleiter H (2005b) Spatialanatomical mapping of NoGo-P3 in the offspring of alcoholics: evidence of cognitive and neural disinhibition as a risk for alcoholism. Clin Neurophysiol 116:1049-61

Kemper TL (1994) Neuroanatomical and neuropathological changes during aging and dementia. In: Albert ML, Knoefel JE (eds) Clinical neurology of aging. Oxford University Press, New York, pp 3-67

Konishi S, Nakajima K, Uchida I, Kikyo H, Kameyama M, Miyashita Y (1999) Common inhibitory mechanism in human inferior prefrontal cortex revealed by event-related functional MRI. Brain 122(Pt 5):981-91

Learned-Miller EG (2006) Data driven image models through continuous joint alignment. IEEE Trans Pattern Anal Mach Intell 28:236-250

Lehericy S, Ducros M, Van de Moortele PF, Francois C, Thivard L, Poupon C, Swindale N, Ugurbil K, Kim DS (2004) Diffusion tensor fiber tracking shows distinct corticostriatal circuits in humans. Ann Neurol 55:522-9

Lewohl J, Wang L, Miles M, Zhang L, Dodd P, Harris R (2000) Gene expression in human alcoholism: microarray analysis of frontal cortex. Alcohol Clin Exp Res 24:1873-1882

Li CS, Luo X, Yan P, Bergquist K, Sinha R (2009) Altered impulse control in alcohol dependence: neural measures of stop signal performance. Alcohol Clin Exp Res 33:740-50

Linden DE (2005) The p300: where in the brain is it produced and what does it tell us? Neuroscientist 11:563-76

Lyons RG (2004) Understanding digital signal processing (2nd ed). Prentice Hall PTR, Prentice Hall PTR

Marner L, Nyengaard JR, Tang Y, Pakkenberg B (2003) Marked loss of myelinated nerve fibers in the human brain with age. J Comp Neurol 462:144-152

Mattis S (1988) Dementia Rating Scale (DRS) Professional Manual. Psychological Assessment Resources, Inc., Psychological Assessment Resources, Inc

Meier-Ruge W, Ulrich J, Bruhlmann M, Meier E (1992) Age-related white matter atrophy in the human brain. Ann N Y Acad Sci 673:260-269

Menon V, Adleman NE, White CD, Glover GH, Reiss AL (2001) Error-related brain activation during a Go/NoGo response inhibition task. Hum Brain Mapp 12:131-43
Mori S, van Zijl PC (2002) Fiber tracking: principles and strategies - a technical review. NMR Biomed 15:468-80

Neeman M, Freyer JP, Sillerud LO (1991) A simple method for obtaining cross-term-free images for diffusion anisotropy studies in NMR microimaging. Magn Reson Med 21:138-43

Nelson HE (1982) The National Adult Reading Test (NART). Nelson Publishing Company, Nashville

Oddy BW, Barry RJ (2009) The relationship of N2 and P3 to inhibitory processing of social drinkers in a Go/NoGo task. Int $\mathrm{J}$ Psychophysiol 72:323-30

Oscar-Berman M, Marinkovic K (2007) Alcohol: effects on neurobehavioral functions and the brain. Neuropsychol Rev 17:239-57

Peters A (2002) The effects of normal aging on myelin and nerve fibers: a review. J Neurocytol 31:581-93

Pfefferbaum A, Sullivan EV (2010) Diffusion MR imaging in neuropsychiatry and aging. In: Gillard J, Waldman A, Barker P (eds) Clinical MR neuroimaging: diffusion, perfusion and spectroscopy. Cambridge University Press, Cambridge, pp 593-617

Pfefferbaum A, Ford JM, Weller BJ, Kopell BS (1985) ERPs to response production and inhibition. Electroencephalogr Clin Neurophysiol 60:423-34

Pfefferbaum A, Lim KO, Zipursky RB, Mathalon DH, Rosenbloom MJ, Lane B, Ha CN, Sullivan EV (1992) Brain gray and white matter volume loss accelerates with aging in chronic alcoholics: a quantitative MRI study. Alcohol Clin Exp Res 16:1078-89

Pfefferbaum A, Rosenbloom MJ, Adalsteinsson E, Sullivan EV (2007) Diffusion tensor imaging with quantitative fibre tracking in HIV infection and alcoholism comorbidity: synergistic white matter damage. Brain 130:48-64

Pfefferbaum A, Rosenbloom MJ, Rohlfing T, Sullivan EV (2009) Degradation of association and projection white matter systems in alcoholism detected with quantitative fiber tracking. Biol Psychiatry 65:680-690

Pfefferbaum A, Rosenbloom MJ, Fama R, Sassoon SA, Sullivan EV (2010) Transcallosal white matter degradation detected with quantitative fiber tracking in alcoholics men and women: selective relations to dissociable functions. Alcohol Clin Exp Res 34:1201-1211

Porjesz B, Begleiter H (2003) Alcoholism and human electrophysiology. Alcohol Res Health 27:153-60

Porjesz B, Rangaswamy M, Kamarajan C, Jones KA, Pasmanabhapillai A, Begleiter H (2005) The utility of neurophysiological markers in the study of alcoholism. Clin Neurophysiol 116:993-1018

Rangaswamy M, Jones KA, Porjesz B, Chorlian DB, Padmanabhapillai A, Kamarajan C, Kuperman S, Rohrbaugh J, O'Connor SJ, Bauer LO, Schuckit MA, Begleiter H (2007) Delta and theta oscillations as risk markers in adolescent offspring of alcoholics. Int J Psychophysiol 63:3-15

Rodriguez Holguin S, Porjesz B, Chorlian DB, Polich J, Begleiter H (1999a) Visual P3a in male alcoholics and controls. Alcohol Clin Exp Res 23:582-91

Rodriguez Holguin S, Porjesz B, Chorlian DB, Polich J, Begleiter H (1999b) Visual P3a in male subjects at high risk for alcoholism. Biol Psychiatry 46:281-91

Rohlfing T, Maurer CR Jr (2003) Nonrigid image registration in sharedmemory multiprocessor environments with application to brains, breasts, and bees. IEEE Trans Inf Technol Biomed 7:16-25

Rohlfing T, Zahr NM, Sullivan EV, Pfefferbaum A (2010) The SRI24 multichannel atlas of normal adult human brain structure. Hum Brain Mapp 31:798-819

Rosenbloom M, Sullivan EV, Pfefferbaum A (2003) Using magnetic resonance imaging and diffusion tensor imaging to assess brain damage in alcoholics. Alcohol Res Health 27:146-52

Rueckert D, Sonoda LI, Hayes C, Hill DL, Leach MO, Hawkes DJ (1999) Nonrigid registration using free-form deformations: application to breast MR images. IEEE Trans Med Imaging 18:712-721 
Salat DH, Tuch DS, Greve DN, van der Kouwe AJW, Hevelone ND, Zaleta AK, Rosen BR, Fischl B, Corkin S, Rosas HD, Dale AM (2005) Age-related alterations in white matter microstructure measured by diffusion tensor imaging. Neurobiol Aging 26:1215-1227

Skinner HA (1982) Development and validation of a lifetime alcohol consumption assessment procedure. Addiction Research Foundation, Addiction Research Foundation

Skinner HA, Sheu WJ (1982) Reliability of alcohol use indices: the lifetime drinking history and the MAST. J Stud Alcohol 43:1157-1170

Smith S (2002) Fast robust automated brain extraction. Hum Brain Mapp 17:143-155

>Song SK, Sun SW, Ramsbottom MJ, Chang C, Russell J, Cross AH (2002) Dysmyelination revealed through MRI as increased radial (but unchanged axial) diffusion of water. Neuroimage 17:142936

Song SK, Sun SW, Ju WK, Lin SJ, Cross AH, Neufeld AH (2003) Diffusion tensor imaging detects and differentiates axon and myelin degeneration in mouse optic nerve after retinal ischemia. Neuroimage 20:1714-22

Song SK, Yoshino J, Le TQ, Lin SJ, Sun SW, Cross AH, Armstrong RC (2005) Demyelination increases radial diffusivity in corpus callosum of mouse brain. Neuroimage 26:132-40

Stadlbauer A, Salomonowitz E, Strunk G, Hammen T, Ganslandt O (2008) Age-related degradation in the central nervous system: assessment with diffusion-tensor imaging and quantitative fiber tracking. Radiology 247:179-88

Stieltjes B, Kaufmann WE, van Zijl PC, Fredericksen K, Pearlson GD, Solaiyappan M, Mori S (2001) Diffusion tensor imaging and axonal tracking in the human brainstem. Neuroimage 14:723-35

Stige S, Fjell AM, Smith L, Lindgren M, Walhovd KB (2007) The development of visual P3a and P3b. Dev Neuropsychol 32:563-84

Sullivan EV, Pfefferbaum A (2005) Neurocircuitry in alcoholism: a substrate of disruption and repair. Psychopharmacol Berl 180:583-94

Sullivan EV, Pfefferbaum A (2006) Diffusion tensor imaging and aging. Neurosci Biobehav Rev 30:749-61

Sullivan EV, Pfefferbaum A (2007) Neuroradiological characterization of normal adult ageing. Br J Radiol 80(Spec No 2):S99108

Sullivan EV, Adalsteinsson E, Pfefferbaum A (2006) Selective agerelated degradation of anterior callosal fiber bundles quantified in vivo with fiber tracking. Cereb Cortex 16:1030-9

Sullivan EV, Rohlfing T, Pfefferbaum A (2010) Quantitative fiber tracking of lateral and interhemispheric white matter systems in normal aging: relations to timed performance. Neurobiol Aging 31:464-481

Sun SW, Liang HF, Le TQ, Armstrong RC, Cross AH, Song SK (2006a) Differential sensitivity of in vivo and ex vivo diffusion tensor imaging to evolving optic nerve injury in mice with retinal ischemia. Neuroimage 32:1195-204
Sun SW, Liang HF, Trinkaus K, Cross AH, Armstrong RC, Song SK (2006b) Noninvasive detection of cuprizone induced axonal damage and demyelination in the mouse corpus callosum. Magn Reson Med 55:302-8

Tallon-Baudry C, Bertrand O, Delpuech C, Permier J (1997) Oscillatory gamma-band $(30-70 \mathrm{~Hz})$ activity induced by a visual search task in humans. J Neurosci 17:722-734

Tarnowska-Dziduszko E, Bertrand E, Szpak G (1995) Morphological changes in the corpus callosum in chronic alcoholism. Folia Neuropathol 33:25-29

Valdes-Hernandez PA, Ojeda-Gonzalez A, Martinez-Montes E, Lage-Castellanos A, Virues-Alba T, Valdes-Urrutia L, ValdesSosa PA (2010) White matter architecture rather than cortical surface area correlates with the EEG alpha rhythm. Neuroimage 49:2328-39

Vallesi A, Stuss DT, McIntosh AR, Picton TW (2009) Age-related differences in processing irrelevant information: evidence from event-related potentials. Neuropsychologia 47:577-86

von Stein A, Sarnthein J (2000) Different frequencies for different scales of cortical integration: from local gamma to long range alpha/theta synchronization. Int J Psychophysiol 38:301-313

Watanabe M (1986) Prefrontal unit activity during delayed conditional Go/No-Go discrimination in the monkey. II. Relation to Go and No-Go responses. Brain Res 382:15-27

Watanabe J, Sugiura M, Sato K, Sato Y, Maeda Y, Matsue Y, Fukuda H, Kawashima R (2002) The human prefrontal and parietal association cortices are involved in NO-GO performances: an event-related fMRI study. Neuroimage 17:1207-16

Wechsler D (1997) Wechsler memory scale-Third Edition. Harcourt Assessments, Harcourt Assessments

Wechsler D (1999) Wechsler abbreviated scale of intelligence. Harcourt Brace and Company, San Diego

Weisbrod M, Kiefer M, Marzinzik F, Spitzer M (2000) Executive control is disturbed in schizophrenia: evidence from eventrelated potentials in a Go/NoGo task. Biol Psychiatry 47:5160

Westlye LT, Walhovd KB, Bjornerud A, Due-Tonnessen P, Fjell AM (2009) Error-related negativity is mediated by fractional anisotropy in the posterior cingulate gyrus - a study combining diffusion tensor imaging and electrophysiology in healthy adults. Cereb Cortex 19:293-304

Woods R, Grafton S, Holmes C, Cherry S, Mazziotta J (1998) Automated image registration: I. General methods and intrasubject, intramodality validation. J Comput Assist Tomogr 22:139-152

Xu D, Mori S, Solaiyappan M, van Zijl PC, Davatzikos C (2002) A framework for callosal fiber distribution analysis. Neuroimage 17:1131-1143

Xue R, van Zijl PC, Crain BJ, Solaiyappan M, Mori S (1999) In vivo three-dimensional reconstruction of rat brain axonal projections by diffusion tensor imaging. Magn Reson Med 42:1123-1127 